\title{
SIGNIFIKANSI PENDEKATAN SOSIOLOGIS TERHADAP STUDI KEISLAMAN
}

\author{
Oleh: \\ Vicky Izza El Rahma ${ }^{1}$ \\ Email: vickyizzaelrahma@yahoo.co.id
}

\begin{abstract}
The sociology approach in Islamic studies has a significant contribution. The object of sociological studies in religious studies is that humans are devoted to the social aspects of their religions (religious communities). In the context of Islam, the dialectical relationship between the immaterial-sacred revelation of God and material-profane social processes is reflected in the decline of the verses of the Mākiyyah and Madāniyyah. By reading religion through a sociological approach, religion will not be reduced only as a set of normative-theological rules that produce black-and-white, right-wrong, halal-haram products, and so on. Religion will always be actual because it is not only applied as a song of revelation and is not ignorant of the real problems faced by society.
\end{abstract}

Key words: approach, sociology, Islamic studies

\section{Pendahuluan}

Tanda tanya terkait mengapa peradaban Islam lebih terbelakang dibandingkan dengan peradaban Barat pertama kali dimunculkan oleh Amir Syakib Arsalan (1869-1946 melalui bukunya yang berjudul Limādha Ta'akhkhara al-Muslimūn wa Limādha Taaddama Ghairahum? Buku ini ditulis oleh Amir Syakib Arsalan bermula dari pertanyaan yang diajukan oleh seorang Jawa bernama Muhammad Basuni Imran. Sejak pertama kali diterbitkan hingga kini, pertanyaan mengenai penyebab kejumudan peradaban Islam dibanding peradaban lain masih terus menuai perdebatan.

Sebagian di antara umat Islam menyakini jalan yang harus ditempuh untuk mengembalikan kejayaan Islam adalah mengembalikan pengamalan-pengamalan ajarannya seperti pada Nabi Muhammad Saw

${ }^{1}$ Dosen Prodi Hukum Pidana Islam Sekolah Tinggi Agama Islam Syaichona Moh. Cholil Bangkalan 
dan para sahabatnya dulu. Mereka nampak memahami secara tekstual hadits yang menyatakan, "Sebaik-baik kamu adalah generasiku, kemudian (generasi yang datang) sesudah mereka, lalu generasi yang datang sesudah mereka." (HR. Bukhāri dan Muslim melalui jalur 'Imrān ibn al-Husain). ${ }^{2}$

Selain kelompok pertama yang disebut di atas, ada juga kelompok kedua yang silau dengan kemajuan peradaban Barat. Sehingga apa pun yang berasal dari Barat direngguk mentah-mentah tanpa melakukan filterasi terlebih dahulu. Bahkan jika perlu, demi bisa meniru Barat, akar budaya serta ajaran Islam pun ditanggalkan. ${ }^{3}$

Ada pula kelompok ketiga yang berupaya mempelajari segala kemajuan yang berasal dari Barat dengan tanpa melepaskan kepribadian dan prinsip-prinsip ajaran Islam. ${ }^{4}$

Terkait perbedaan sikap yang ditunjukkan kelompok-kelompok tersebut, seorang filosof Mesir kontemporer, Zaki Najib Mahmud, dalam bukunya Hādzā al-'Asrwa Thaqāfatuhu, menyadari bahwa penyikapan terhadap tradisi dan modernitas, bukan perkara yang mudah. Sebab kemajuan kontemporer adalah produk yang dihasilkan oleh peradaban lain yang dipersilahkan masuk ke rumah umat Islam. Zaki Najib Mahmud menganalogikannya dengan raksasa yang tiba-tiba telah berdiri di depan rumah. Saat itu pemilik rumah tentu kebingungan tentang apa yang harus dilakukannya; membuang jauh-jauh perabotan rumah agar raksasa bisa masuk ke dalam rumah, ataukah mengatur ulang perabotan yang ada agar sang tamu bisa masuk ke dalam rumah dengan leluasa, dan pada saat yang sama tidak ada perabotan rumah penting yang dibuang atau diabaikan pemilik rumah. 5

Salah satu produk kemajuan kontemporer Barat yang tengah ramai diperbincangkan adalah integrasi ilmu-ilmu sosial, seperti: sosiologi,

${ }^{2}$ M. Quraish Shihab, Membumikan al-Qur'an 2: Memfungsikan Wahyu dalam Kehidupan, Cet. I, (Jakarta: LenteraHati, 2010), 312.

${ }^{3}$ Ibid.

${ }^{4}$ Ibid.

${ }^{5}$ Ibid., 457. 
antropologi, politik, dan ekonomi-dalam studi keagamaan.6 Pada titik ini, sekali lagi terjadi perdebatan, bisakah agama yang sifatnya sacral ditelaah dengan pendekatan-pendekatan sosial yang bersifat profan? Mungkinkah melihat agama dari sudut pandang historisitas? Bukankah selama ini aspek normativitas telah menjadi cirri khas dari agama?

Harus diakui memang, jika sampai saat ini, masih terdapat tensi ketegangan yang cukup tinggi antara pendekatan yang bercorak normatif dan historis. ${ }^{7}$ Pendekatan pertama, lantaran bermula dari teks-teks suci keagamaan, membuatnya bersifat literalis, tekstualis, dan skriptualis. Sehingga cenderung untuk menolak pendekatan kedua. Bagi pendukung pendekatan normativitas dalam studi keagamaan, pendekatan historis hanya akan mereduksi pemahaman agama pada aspek eksternal lahiriah dan kurang menyentuh pada aspek internal batiniah. ${ }^{8}$

Di sisi lain, penyokong mazhab historisitas balik menuduh mazhab normativitas akan membuat pemahaman agama menjadi absolut. Hal ini dimungkinkan lantaran pendekatan normative cenderung mengabsolutkan teks, tanpa berusaha menelaah lebih jauh apa yang melatarbelakangi munculnya berbagai teks keagamaan tersebut. ${ }^{9}$

Berangkat dari tarik ulur antarkelompok, sebagaimana diurai sekilas di atas, tulisan ini selanjutnya berupaya untuk menunjukkan posibilitas dan signifikansi yang dihidangkan oleh ilmu-ilmu sosial-dalam konteks tulisan ini dikhususkan pada sosiologi - terhadap kajian Islamic Studies.

\section{Cara Pandang Sosiologi: Menelaah Posibilitas Studi Keislaman dengan Pendekatan Sosiologis}

Kata sosiologi berasal dari kata Latin socius yang artinya teman, dan kata Yunani logos yang berarti cerita. Kata sosiologi pertama kali muncul

${ }^{6}$ Di Indonesia upaya integrasi ilmu-ilmu sosial pada kajian keagamaan dimulai gaungnya oleh Mukti Ali pada tahun 1970-a. Lihat M. Atho Mudzhar, Pendekatan Studi Islam dalam Teori dan Praktek, Cet. I, (Yogyakarta: PustakaPelajar, 1998), 1.

${ }^{7}$ Jean Jacobs Waardenburgh, Islam: Historical, Social, and Political Prespectives, (Berlin: de Gruyter, 2002), 189.

${ }^{8}$ M. Amin Abdullah, "Kata Pengantar" dalam Studi Agama: Normativitas atau Historisistas?, Cet. I, (Yogyakarta: Pustaka Pelajar, 1996), v.

${ }^{9}$ Ibid., vi. 
dalam buku yang berjudul "Cours De Philosophie Positive" karya August Comte (1798-1857).10

Beragam pendapat para pakar diajukan untuk membatasi objek kajian sosiologi. Max Weber, misalnya, menekankan sosiologi sebagai ilmu yang berupaya memahamai tindakan-tindakan sosial.11 Sementara Allan Johnson mendefinisikan sosiologi sebagai ilmu yang mempelajari kehidupan dan perilaku, terutama, dalam kaitannya dengan suatu sitem sosial; bagaimana sistem tersebut mempengaruhi orang dan, sebaliknya, bagaiamana orang yang terlibat di dalamnya mempengaruhi sistem tersebut. ${ }^{12}$

Lebih spesifik lagi, Selo Soemarjan dan Soelaiman Soemantri membatasi sosiologi sebagai ilmu yang mempelajari struktur sosial (yaitu keseluruhan jalinan antara unsur-unsur sosial yang pokok seperti kaidahkaidah sosial, lembaga-lembaga sosial, kelompok-kelompok sosial, dan lapisan sosial) serta proses-proses sosial (yang berupa pengaruh timbale balik antarberbagai kehidupan bersama, seperti kehidupan ekonomi dan kehidupan politik, kehidupan hukum dan kehidupan agama, dan lain sebagainya). ${ }^{13}$

Adapun Soejono Soekamto mengemukakan bahwa sosiologi merupakan ilmu yang memusatkan perhatiaannya pada aspek kemasyarakatan dan berupaya mendapatkan pola umum dalam kehidupan bermasyarakat. ${ }^{14}$

Dari beberapa definisi yang disebut di atas, didapat gambaran bahwa objek kajian sosiologi dalam kajian keagamaan adalah manusia yang dikhususkan pada aspek sosial keberagamaannya (masyarakat beragama). Dalam konteks keislaman, hubungan dialektika antara wahyu Tuhan yang immaterial-sakral dan proses sosial yang material-profan tergambar dari turunnya ayat-ayat Mākiyyah dan Madāniyyah.

\footnotetext{
${ }^{10}$ Elly M. Setiadidan Usman Kolip, Pengantar Sosiologi: Pemahaman Fakta, dan Gejala, Permasalahan Sosial, Cet. IV, (Jakarta: Prenada Media, 2015), 1-2.

${ }^{11}$ Elly M. Setiadidan Usman Kolip, Pengantar Sosiologi...3.

${ }^{12}$ Ibid.

${ }^{13}$ Soerjono Soekamto, Sosiologi: Suatu Pengantar, Cet. II, (Jakarta: Rajawali Press, 1986), 15.

${ }^{14}$ Ibid., 16.
} 
Salah satu hal yang menarik terkait proses turunnya wahyu adalah ayat-ayat al-Quran tidak diturunkan dalam ruang hampa sejarah. Dalam artian bahwa sebagian besar ayat-ayat al-Quran memiliki sebab-sebab turun (asbāb al-nuzūl) berupa peristiwa-peristiwa sosial yang dihadapi oleh Nabi Muhammad Saw dan para sahabatnya. Sehingga ayat-ayat tersebut seolah-olah ikut memecahkan persoalan-persoalan itu, atau memberikan pedoman dan ketetapan status hukum bagi persoalan-persoalan yang dihadapi.

Sekadar contoh, saat Nabi Muhammad Saw hamper patah semangat dalam berjuang karena mendapat banyak fitnah, ayat-ayat al-Quran turun menghibur Nabi dan para pengikutnya dengan ayat-ayat yang menganjurkan kesabaran dan Allah akan senantiasa mendampingi orangorang yang sabar. Begitu pula ketika Nabi Saw berada di Madinah dan tengah menghadapi orang-orang munafik dengan segala tipu muslihatnya, maka segera turun ayat-ayat yang kemudian dikelompokkan dalam Surah al-Munāfiqūn yang melukiskan sifat-sifat orang munafik, dan memperingatkan agar orang-orang mukmin berhati-hati terhadap mereka.

Pada proses turunnya wahyu, al-Quran benar-benar hadits secara aktual-terlibat langsung dalam proses sosial di zaman Rasulullah Saw. Namun setelah Rasulullah wafat maka umat manusia harus mengusahakan sendiri agar al-Quran tetap aktual. Salah satu caranya, tentu dengan tidak memisahkan al-Quran dari konteks sosialnya kini. Namun perlu menjadi catatan karena ajaran Islam telah sempurna dengan turunnya ayat terakhir ayat ketiga dari Surah al-Māidah, maka domain hukumnya tidak mengalami perkembangan. (perubahan). ${ }^{15}$ Domain ini tentu sangat berbeda dengan aspek sosial ke masyarakat yang senantiasa mengalami perubahan. Di sinilah sosiologi hadir untuk mengisi kekosongan tersebut.

Ketika pisau analisis dalam sosiologi dimasukkan pada ranah agama, beberapa pertanyaan yang muncul dalam studi sosiologi agama adalah: Mengapa manusia memeluk agama? Mengapa agama begitu lestari dan

${ }^{15}$ Untuk menggali lebih lanjut tentang kondisi hukum Islam yang tidak mengalami perubahan, namun pada saat yang sama juga bisa terus sesuai di setiap masa dan tempat silahkan baca buku al-Islām wa al'Aql karya 'Abd al-Halīm Mahmūd. 
selalu dibutuhkan manusia? Bagaimana agama bisa menjadi acuan moral bagi segala tindakan manusia (frame of reference of action)? Mengapa manusia mengadakan upacara ritual bersama? Mengapa agama mampu menjadi factor integrasi masyarakat? Dan apa sebabnya agama mampu melahirkan solidaritas yang kuat di antara sesame penganut agama?16

Bila melihat daftar pertanyaan-pertanyaan di atas, tampak bahwa objek kajian dari sosiologi agama tidak pada kapasitas menilai benar tidaknya cara beragama seseorang. Tidak ada singularitas kebenaran ketika agama didekati dengan ilmu sosiologi. Sebab lokusnya adalah bidang sosial tertentu dengan analisis kasus per kasus.

\section{Sumber-Sumber Pengetahuan: Menakar Signifikansi Pendekatan Sosiologis dalam Studi Keislaman}

Setelah menjajaki kemungkinan menggunakan pendekatan sosiologi dalam studi keislaman, pertanyaan selanjutnya yang harus dijawab adalah apa signifikansi yang didapatkan Islamic studies dari pendekatan sosiologi. Pertanyaan ini penting untuk ditindaklanjuti, sebab semua hal yang mungkin dilakukan tidak dengan sendirinya menjadi penting pula untuk dilakukan.

Guna menakar signifikansi yang diberikan oleh sosiologi terhadap kajian keislaman, penulis akan memulainya dari penjabaran sumbersumber keilmuan. Tujuan akhirnya agar terlihat objek-objek apa saja dalam ilmu pengetahuan yang akan ter-cover oleh sosiologi.

Meski tetap masih menyisakan benang merah yang bisa ditarik, ada beberapa perbedaan pendapat tentang sumber-sumber yang bisa dijadikan tempat bermulanya pengetahuan. Jujun S. Suriasumantri, misalnya, menunjuk rasionalisme, empirisisme, intuisi dan wahyu sebagai empat sumber pengetahuan. ${ }^{17}$

Amsal Bakhtiar, dalam buku Filsafat Agama, merujuk empirisisme, rasionalisme dan iluminasionisme sebagai tiga sumber asal-usul 2009), 46.

${ }^{16}$ Dadang Kahmad, Sosiologi Agama,Cer. V, (Bandung: Remaja Rosda Karya,

${ }^{17}$ Jujun S. Suriasumantri, Filsafat Ilmu, Sebuah Pengantar Populer, Cet. XVI (Jakarta, Pustaka Sinar Harapan, 2003), hlm. 50-54. 
pengetahuan. ${ }^{18}$ Sedangkan dalam bukunya yang terbit lebih belakangan, Filsafat Ilmu, ${ }^{19}$ Amsal Bakhtiar menyebutkan rasionalisme, empirisisme, intuisi dan wahyu sebagaisumber-sumber pengetahuan.

Di sisi lain, sedikit berbeda dari pendapat Jujun S. Suriasumantri Harold $\mathrm{H}$. Titus dkk. Menunjuk otoritas, empirisisme, rasionalisme dan intuisi sebagai empat sumber pengetahuan. ${ }^{20}$

a. Pengalaman Empiris

Penganut empirisme meyakini bahwa segala yang diketahui selalu bermula dari segala yang dialami panca indera. Maka apa yang dilihat, didengar, disentuh, dibaui dan dicecap, merupakan wilayah pengetahuan.

Empirisme memberikan penekanan sangat kuat pada kekuatan persepsi dan observasi manusia, atau segala yang ditangkap panca indera dari lingkungan. Singkatnya, pengetahuan didapat dengan membentuk gagasan-gagasan yang sejalan dengan beragam fakta yang diobservasi.

Para pendukung empirisme beranggapan bahwa "kita mengetahui apa yang ditemukan oleh panca indera kita". Dalam empirisme dinyatakan bahwa secara esensial pengetahuan tidak lain dari sensasi dan, karena itu, tidak ada pengetahuan yang tidak bersumber dari sensasi.21 David Hume, seperti dikutip Amsal Bakhtiar, berpandangan bahwa manusia sebenarnya tidak pernah memiliki pengetahuan

${ }^{18}$ Amsal Bakhtiar, Filsafat Agama, Cet. II, (Jakarta, Logos Wacana Ilmu, 1999), 41- 53.

${ }^{19}$ Amsal Bakhtiar, Filsafat Ilmu, (Jakarta, Rajawali, 2004), 98-110.

${ }^{20}$ Harold H. Titus et al., Living Issues in Philosophy, $7^{\text {th }}$ Edition, (New York: D. Van Nostrad Company, 1979), 170-175.

Sebagai bahan perbandingan, Harold H. Titus dkk. menjelaskan juga bahwa dalam tradisi para filsuf Hindu, misalnya, ada tiga sumber pengetahuan: kitab suci, rasio dan pengalaman. Sementara dalam tradisi Budha, tiga sumber itu meliputi: rasio, pengalaman dan intuisi. Ibid, p. 179.

Tapi sedikit berbeda dari penjelasan Harold H. Titus dkk, dalam sebuah tulisan berjudul "The Four Sources of Knowledge," Sri Swami Sivananda menyebut instinct, reason, intuition, dan direct knowledgeof Brahman (God) or Brahma-Jnana (knowledge of God) sebagaiempat sumber pengetahuan bagi para filsuf Budha. Lihat, http://www.dlshq.org/messages/knowledge.htm.

${ }^{21}$ Harold H. Titus, et. al., Living Issues in Philosophy..., 171. 
bawaan. Sumber pengetahuan yang hakiki adalah pengamatan dan pengalaman lahiriah maupun batiniahnya. ${ }^{22}$

Para penganut empirisme meyakini bahwa pengetahuan manusia itu tidak pernah didapatkan lewat proses penalaran rasional yang abstrak tapi justru lewat pengalaman yang konkrit. ${ }^{23}$

b. Rasio

Berbeda dari empirisme, rasionalisme menempatkan akal sebagai sumber pengetahuan. Rasionalisme adalah pandangan yang menyatakan bahwa "apa pun yang kita ketahui sesungguhnya tidak lain dari apa yang kita pikirkan". Rasionalisme beranggapan bahwa "pikiran memiliki kemampuan untuk menyingkap dan menemukan kebenaran". Atau, dengan kata lain, "pengetahuan didapatkan dengan cara membandingkan ide dengan ide lainnya". ${ }^{24}$

Dalam menegaskan kekuatan pikiran manusia dan kontribusinya dalam pengembangan pengetahuan, kaum rasionalis menilai bahwa panca indera sebenarnya tidak akan pernah mampu memberikan penilaian yang secara universal bisa dinilai valid dan koheren. Sensasisensasi dan pengalaman-pengalaman yang kita dapatkan lewat panca indera kita, menurut para pendukung rasionalisme, sejatinya tak lebih dari "bahan baku mentah pengetahuan" (a raw material of knowledge). ${ }^{25}$

Dengan kata lain, para penganut rasionalisme memang mengakui peran panca indera dalam mengumpulkan data untuk menemukan jalan menuju pengetahuan. Hanya saja, dalam pandangan mereka, untuk mencapai pengetahuan, tetap saja akal yang menjadi sarana penghubung antar berbagai data tersebut. ${ }^{26}$

c. Intuisi

${ }^{22}$ Amsal Bakhtiar, Filsafat Agama..., 42-43; Amsal Bakhtiar, Filsafat Ilmu..., 98102.

${ }^{23}$ Jujun S. Suriasumantri, Filsafat Ilmu...., 51.

${ }^{24}$ Harold H. Titus et al., Living Issues in Philosophy..., 172; juga A.R. Lacey, A Dictionary of Philosophy, New Edition, (London, Routledge \& Kegan Paul Ltd., 2000), 286, yang mendefinisikan rasionalisme sebagai "Any view appealing to reason as a source of knowledge or justification".

${ }^{25}$ Harold H. Titus et al., Living Issues in Philosophy..., 173.

${ }^{26}$ Amsal Bakhtiar, Filsafat Agama..., 45. 
Intuisi didefinisikan oleh Harorld H. Titus dkk. sebagai "pemahaman atas pengetahuan secara langsung yang bukan berasal dari suatu penalaran sadar" ("the direct apprehension of knowledge that is not the result of conscious reasoning").27 Sedangkan Jujun S. Suriasumantri mendefinisikannya sebagai "pengetahuan yang didapatkan tanpa melalui proses penalaran tertentu". ${ }^{28}$

Amsal Bakhtiar, di sisi lain, dengan memosisikan intuisi sebagai sinonim dari istilah makrifah dalam tradisi tasawuf, menjelaskannya sebagai "pengetahuan yang datang dari Tuhan melalui pencerahan dan penyinaran". Menurutnya, jika dalam tradisi filsafat Barat intuisi bisa dicapai lewat upaya perenungan dan pemikiran yang konsisten, maka makrifah diperoleh melalui proses perenungan yang mendapatkan penyinaran atau iluminasi dari Tuhan. ${ }^{29}$

Sampai titik ini, kendati Amsal Bakhtiar tidak menyebutkan wahyu secara eksplisit sebagai sumber pengetahuan, dengan memadankan antara intuisi dengan ma'rifah, ia sebenarnya hampir sepenuhnya sejalan dengan pendapat Jujun S. Suriasumantri. Apalagi, di buku keduanya (Filsafat Ilmu), Amsal pun akhirnya secara eksplisit menyebut wahyu sebgai salah satu sumber pengetahuan. Dan, dengan beberapa catatan penting yang akan dipaparkan lebih lanjut di bagian lain dalam tulisan ini, Harorld H. Titus dkk pun dalam tingkat tertentu sebenarnya menunjuk wahyu sebagai sumber lain bagi pengetahuan.

Harorld H. Titus dkk, selain menilai intuisi sebagai “jenis pengetahuan yang lebih tinggi" (a higher kind of knowledge), juga memandang intuisi seperti yang diperoleh melalui "ungkapanungkapan mistis memungkinkan kita untuk mencapai pengetahuan langsung yang melampaui pengetahuan yang diperoleh melalui nalar dan panca indera" ("Intuition as found in mystical expressions may enable us to gain immediate knowledge which transcends knowledge gained through reason and senses"). ${ }^{30}$

${ }^{27}$ Harold H. Titus et al., Living Issues in Philosophy..., 174.

${ }^{28}$ Jujun S. Suriasumantri, Filsafat Ilmu ..., 53.

${ }^{29}$ Amsal Bakhtiar, Filsafat Agama..., 50.

${ }^{30}$ Harold H. Titus et al., Living Issues in Philosophy..., 175. 
d. Wahyu

Wahyu adalah pengetahuan yang didasarkan pada kepercayaan atas hal-hal yang bersifat supranatural. Wahyu tidak sekadar membicarakan persoalan-persoalan kekinian yang bisa dicapai panca indera tapi juga mencakup soal-soal transendental. Wahyu disampaikan oleh Tuhan kepada manusia melalui para nabi-Nya. ${ }^{31}$

e. Otoritas (Kesaksian)

Bagaimanakah kita bisa mengetahui bahwa Socrates dan Julius Caesar benar-benar pernah hidup dan kita bisa sampai pada suatu keyakinan bahwa keduanya bukanlah tokoh-tokoh fiktif hasil rekaan semata? Tokoh yang dipertanyakan tentu saja bisa kita ganti dengan Gadjah Mada, Hayam Wuruk, atau Wali Songo, misalnya.

Untuk mendapatkan jawaban meyakinkan atas pertanyaanpertanyaan sejenis ini, menurut Harorld H. Titus dkk., jalannya adalah lewat kesaksian (testimony) orang-orang yang hidup sezaman dengan tokoh-tokoh tersebut dan dari tuturan para sejarawan. Bersandar kepada keaksian orang lain (otoritas) itulah, menurut Harorld H. Titus dkk., jalan yang paling lumrah untuk mengetahui kebenaran dan mencapai segala pengetahuan yang berkaitan dengan masa lalu.

Untuk mencapai pengetahuan tersebut, sama sekali tidak pernah bisa disandarkan baik kepada intuisi, penalaran (rasionalisme) maupun pengalaman pribadi (empirisme). Karena itu, dalam pandangan Harorld H. Titus dkk., selain tiga sumber pengetahuan lainnya, otoritas atau kesaksian (authority, testimony) tak diragukan lagi merupakan salah satu sumber lain bagi pengetahuan. ${ }^{32}$

Hanya saja, kita boleh dan harus bersandar kepada kesaksian atau otoritas tersebut, sepanjang kita tidak mampu melakukan penelaahan sendiri. Dan yang tak kalah penting, otoritas sebagai tempat bersandar itu pun harus betul-betul individu-individu yang memiliki integritas. Di samping, kesaksian dan otoritas itu pun harus selalu diposisikan tidak lebih dari sumber pengetahuan sekunder. ${ }^{33}$

\footnotetext{
${ }^{31}$ Jujun S. Suriasumantri, Filsafat Ilmu..., 54.

${ }^{32}$ Ibid., 170.

${ }^{33}$ Ibid.
} 
Setelah mengkaji keempat sumber pengetahuan yang disebutkan di atas, tampak bahwa masing-masing sumber memiliki kelebihan sekaligus kekurangan masing-masing. Empirisme, misalnya, berkontribusi sangat besar menopang capaian-capaian ilmu pengetahuan modern. Karena lebih banyak berkaitan dengan fakta-fakta, ilmu pengetahuan modern bisa dikatakan sepenuhnya bersifat empiris.

Hanya saja, ketika para pendukung empirisme menyandarkan diri pada pengetahuan yang sepenuhnya bersifat empiris itu, mereka pun sebenarnya tetap saja harus waspada atas kehadiran beragam prasangka dan perasaan yang juga potensial mendistorsi pandangan mereka saat "memilih fakta-fakta" yang dianggap mendukung kesimpulan-kesimpulan yang dibuat. Sebab, mengutip pendapat Harold H. Titus dkk. "pengetahuan kita dipengaruhi dan diwarnai oleh unsur-unsur yang bersifat subjektif-personal" ("our knowledge influenced by a personal and subjective coloration"). ${ }^{34}$

Empirisme, karena itu, sebenarnya memiliki beberapa kelemahan yang terkadang bersifat menipu. Keterbatasan indera penglihatan kita saat melihat suatu benda yang sesungguhnya besar menjadi kecil ketika memandangnya dari jarak yang cukup jauh; melihat benda lurus seolaholah bengkok saat ia ditaruh dalam air; merasakan gula sebagai sesuatu yang pahit saat sakit malaria; adalah beberapa contoh yang menunjukkan kelemahan dan keterbatasan indera sebagai sandaran empirisme. ${ }^{35}$

Rasionalisme, di titik lain, juga mengandung kekurangan. Lantaran berlebihan menjadikan kekuatan rasio, rasionalisme pun potensial memiliki klaim bahwa mereka mampu mencapai kebenaran tak tersanggah yang bersifat independen dan tak memiliki hubungan apa pun dengan indera (pengalaman). Kaum rasionalis, dengan kata lain, mengklaim mampu menyuguhkan kebenaran hakiki (genuine knowledge) dengan hanya bersandar kepada kekuatan pikiran.

Lalu, bagaimanakah posisi intuisi (iluminisionisme) dan wahyu sebagai sumber pengetahuan? Di luar posisinya yang sama-sama absah sebagai sumber pengetahuan, intuisi (iluminisionisme) dan wahyu tidak

\footnotetext{
${ }^{34}$ Harold H. Titus et al., Living Issues in Philosophy..., 172.

${ }^{35}$ Amsal Bakhtiar, Filsafat Agama..., 102.
} 
seharusnya diletakkan secara mandiri dan berdiri sendiri saat dijadikan sebagai sumber ilmu. Sebab tanpa ditopang kekuatan rasio (rasionalisme) dan data-data empiris (empirisme) intuisi dan wahyu akan gampang menggiring manusia kepada klaim-klaim yang tak bisa dipertanggungjawabkan. Dalam pendapatnya Harorld H. Titus dkk, intuisi dan wahyu, "goes astray very easily and may lead to absurd claims unless it is controlled and checked by reason and the senses". 36

Sama halnya dengan posisi intuisi (iluminisionisme) dan wahyu yang tidak mungkin menjadi sumber kebenaran tanpa topangan memadai dari kekuatan rasio dan panca indera; sebagai salah satu sumber sekunder pengetahuan, otoritas pun sangat berbahaya jika manusia menjadikannya sebagai sandaran pengetahuan tanpa diikuti pencarian lebih jauh tentang benar-salahnya. ${ }^{37}$

Maka, seperti pemaparan deskriptif-analitis sebelumnya, sumbersumber yang selama ini dianggap sebagai sumber-sumber yang abash bagi pengetahuan itu pada akhirnya tidaklah bersifat independen antarsatu sumber dengan sumber-sumber yang lainnya. Semua sumber-sumber itu, singkatnya, sesungguhnya bersifat saling melengkapi dan tidak mungkin dirujuk secara terpisah tanpa dukungan sumber-sumber yang lainnya.

Dalam konteks pendekatan sosiologis dalam studi keislaman, penggabungan semua sumber pengetahuan memungkinkan terkuaknya pengetahuan yang lebih seimbang dan tidak berat sebelah, serta mampu mengurai problem real yang dihadapi oleh masyarakat jelas merupakan pilihan yang paling ideal.

Sebagai tamsil, bila ditilik dari kacamata teologis, maka sampai kapanpun kajian tentang perzinahan akan menghasilkan simpul yang sama, yakni keharaman hukumnya. Namun bila persoalan zina hanya diurai sebatas keharaman mendekati atau melakukannya saja, maka ia tidak akan berdampak luas, lebih-lebih bagi mereka yang sudah terlanjur akrab dengannya. Karenanya kajian tentang zina harus diteruskan sampai pada jawaban dari solusi apa yang diberikan oleh agama untuk, minimal, mengurangi praktik perzinahan dan dampak negatif yang ditimbulkan

\footnotetext{
${ }^{36}$ Ibid., 177-178.

${ }^{37}$ Ibid., 170-171.
} 
olehnya. Dan upaya untuk menghidangkan solusi tersebut tidak cukup hanya dengan metode rasionalis yang cenderung memilih penalaran deduktif ketimbang observasi yang bersifat empiris. Sebab, dengan penalaran deduktif tersebut, mereka boleh jadi sampai kepada sebuah sistem pemikiran yang logis tapi tidak memiliki relevansi dalam kehidupan nyata.

Contoh lain adalah proyek penanggulangan kemiskinan. Dalam Surah al-Mā'ūn dinyatakan bahwa orang yang paling mendustakan agama ialah orang yang mengerjakan ibadah (shalat) sembari abai pada anak-anak yatim yang terlantar dan orang-orang miskin yang kelaparan. Pertanyaan yang layak dimunculkan kemudian adalah bagaiamana mungkin, misalnya, umat Islam mengimplementasikan perintah dalam Surah alMā'ūn untuk muslim menolong kaum duafa dan anak yatim bila sebelumnya tidak dilakukan pembacaan empiris-rasionalis terhadap proses eksploitasi sosial yang menyingkirkan kelompok mustd'afin.

Manfaat lain dari integrasi sosiologi terhadap Islamic Studies adalah pengembangan model sosioanalisis dalam pembacaan gagasan wahyu. Dengan model sosioanalisis, seorang dai-dengan segala otoritasnyamengambil peran layaknya dokter-dengan kapasitas keilmuannya-yang berkewajiban menyembuhkan pasien dengan terlebih dahulu melakukan observasi dan mengetahui secara pasti jenis dan letak penyakit pasien. Model dakwah semacam ini, terasa semakin mendesak untuk digalakkan sebab selama ini model dakwah yang kerap diterapkan adalah psikoanalisis agama. Misalnya ketika seorang dai menceritakan kisah Isra' Mi'raj-seperti terjadi apa adanya-tanpa mengajak para audiens untuk mengkonfrontasikannya dengan kenyataan-kenyataan sosial yang aktual. ${ }^{38}$

\section{Penutup}

Di antara kekhawatiran yang dimiliki oleh pendukung pendekatan normativitas jika agama didekati dengan pendekatan historis-sosiologis adalah desakralisasi agama. Kekhawatiran ini, nampaknya akan teratasi

\footnotetext{
${ }^{38}$ Moeslim Abdurrahman, Islam Sebagai Kritik Sosial, (Jakarta: Penerbit Erlangga,
} 2003), 117. 
bila disadari bahwa pusat perhatian dari integrasi ilmu sosiol dan ilmu agama adalah aspek sosial. Sekali lagi ditekankah bahwa tidak ada singularitas kebenaran dalam lokus ini.

Dengan membaca agama lewat pendekatan sosiologis, agama tidak akan tereduksi hanya sebagai seperangkat aturan normatif-teologis yang menghasilkan produk hitam-putih, benar-salah, halal-haram, dan seterusnya. Agama justru akan senantiasa aktual karena ia tidak hanya diberlakukan sebatas kidung wahyu dan tidak pula abai terhadap problem real yang dihadapi oleh masyarakat.

Sebaliknya, bila pola pengkajian agama secara teologis terus dipertahankan dengan mengesampingkan aspek sosiologis, maka sangat mungkin agama hanya akan didengungkan di masjid-masjid. Tidak mempan didengungkan di pasar-pasar, di kantor-kantor, di sekolahsekolah, dan dimana saja. Pun demikian jika pola pendekatan normatif tetap dijalankan tanpa dibarengi pendekatan historis, maka tidak mustahil agama hanya akan diingat ketika proses kelahiran, pernikahan, dan kematian. Dan pada akhirnya agama akan ditinggalkan oleh penganutnya.

\section{DAFTAR RUJUKAN}

Abdullah, M. Amin. 1996. "Kata Pengantar" dalamStudi Agama: NormativitasatauHistorisistas?, Cet. I. Yogyakarta: Pustaka Pelajar.

Abdurrahman, Moeslim. 2003. Islam Sebagai Kritik Sosial. Jakarta: Penerbit Erlangga.

Bakhtiar, Amsal. 1999. Filsafat Agama, Cet. II. Jakarta: Logos Wacana Ilmu.

Bakhtiar, Amsal. 2004. Filsafat Ilmu, Cet. I. Jakarta: Rajawali.

Echol, John M., dan Hassan Shadily. 2000. Kamus Inggris-Indonesia, Cet. XXIV. Jakarta: Gramedia Pustaka Utama. 
Kahmad, Dadang. 2009. Sosiologi Agama, Cet. V. Bandung: Remaja Rosda Karya.

Lacey, A.R.. 2000. A Dictionary of Philosophy, New Edition. London: Routledge \& Kegan Paul Ltd..

Mudzhar, M. Atho. 1998. Pendekatan Studi Islam dalam Teori dan Praktik, Cet. I. Yogyakarta: Pustaka Pelajar.

Setiadi, Elly M. dan Usman Kolip. 2015. Pengantar Sosiologi: Pemahaman Fakta, dan Gejala, Permasalahan Sosial, Cet. IV. Jakarta: Prenada Media.

Shihab, M. Quraish. 2010. Membumikan al-Qur'an 2: Memfungsikan Wahyu dalamKehidupan. Cet. I. Jakarta: Lentera Hati.

Sivananda, Sri Swami, "The Four Sources of Knowledge," dalam http://www.dlshq.org/messages/knowledge.htm.

Soekamto, Soerjon. 1996. Sosiologi: SuatuPengantar, Cet. II. Jakarta: Rajawali Press.

Suriasumantri, Jujun S. 2003. Filsafat Ilmu, Sebuah Pengantar Populer, Cet. XVI. Jakarta: Pustaka Sinar Harapan.

Titus, Harold H., et al., 1979. Living Issues in Philosophy. $7^{\text {th }}$ Edition. New York: D. Van Nostrad Company.

Waardenburgh, Jean Jacobs. 2002. Islam: Historical, Social, and Political Prespectives. Berlin: de Gruyter. 